\title{
Clinical and prognostic evaluation of familial hypertrophic cardiomyopathy in two South African families with different cardiac $\beta$ myosin heavy chain gene mutations
}

\author{
Berthold M Posen, Johanna C Moolman, Valerie A Corfield, Paul A Brink
}

Department of Internal Medicine, University of Stellenbosch Medical School and Tygerberg Hospital, Tygerberg, South Africa

P A Brink

B M Posen

University of

Stellenbosch and

Medical Research

Council Centre for

Molecular and

Cellular Biology,

Department of

Medical Physiology

and Biochemistry,

University of

Stellenbosch Medical

School, Tygerberg,

South Africa

V A Corfield

J C Moolman

Correspondence to

Dr V A Corfield,

Department of Medical

Biochemistry, PO Box

Biochemistry, PO Box

Republic of South Africa.

Accepted for publication

21 November 1994

\begin{abstract}
Background-Familial hypertrophic cardiomyopathy is the most common inherited cardiac disorder, with sudden cardiac death at a young age the most frequent cause of death in affected individuals. Some cases of familial hypertrophic cardiomyopathy are caused by missense mutations of the $\beta$ myosin heavy chain ( $\beta$ MHC) gene on chromosome 14 and at least 17 such mutations have been described. Recent reports suggest that a correlation exists between a specific $\beta$ MHC gene mutation and prognosis in familial hypertrophic cardiomyopathy. This premise is currently being used as a basis to provide counselling for affected families. This mutation/prognosis association, however, has not been widely assessed as yet. The clinical and prognostic features of two South African families of mixed racial descent, in which different $\beta$ MHC gene mutations were segregating, were studied to evaluate this correlation. The results were compared with those of previously published reports of European families carrying the same mutations.
\end{abstract}

Methods-The $\beta$ MHC gene missense mutations in two affected families were identified by single strand conformation polymorphism analysis and sequencing (pedigree 106: Arg403Trp; pedigree 108: Arg249Gln). All family members were subjected to genotypic analysis using polymerase chain reaction amplification and restriction enzyme based mutation detection techniques. Clinical, electrocardiographic, and echocardiographic studies were performed on genotypically affected individuals in these two kindreds.

Results-The number of individuals identified in pedigree 106 with the Arg403Trp mutation was 32.10 individuals bore the Arg249GIn mutation in pedigree 108. The penetrance rate in adults (equal to or greater than 16 years), using the strict echocardiographic criterion of maximum left ventricular wall thickness $\geqslant 13 \mathrm{~mm}$, was $25 \%$ for pedigree 106 and $33 \%$ for pedigree 108. Familial hypertrophic cardiomyopathy compatible electrocardiographic and echocardiographic abnormalities were seen in $\mathbf{6 0 \%}$ of genotypically positive individuals aged $\geqslant 16$ years in pedigree 106 and $80 \%$ in pedigree 108. The prognosis was uniformly benign in the two families. For pedigree 106 this corresponded to a report of no early sudden cardiac deaths in a French family with the Arg403Trp mutation. For pedigree 108 the absence of such deaths was in apparent contrast to the four cases reported in 24 genotypically affected individuals in a study of a kindred of European ancestry bearing the Arg249Gln mutation.

Conclusion-This study of a large South African kindred confirmed the benign nature of the Arg403Trp mutation suggested in a previous report. The number and the relatively young age of affected individuals in a second South African family must be considered when comparing the absence of familial hypertrophic cardiomyopathy associated deaths with the intermediate survival reported for the Arg249Gln mutation in a European family. This investigation lends support to current evidence relating specific $\beta$ MHC gene mutations to prognosis, which may be used as a basis to provide counselling for affected families.

(Br Heart F 1995;74:40-46)

Keywords: familial hypertrophic cardiomyopathy; car$\operatorname{diac} \beta$ myosin heavy chain gene mutation; genotypic analysis

Hypertrophic cardiomyopathy is a disorder characterised by non-dilated ventricular hypertrophy, which exists in the absence of a cardiac or systemic disease, such as hypertension or valvular disease, capable of producing a similar clinical picture. ${ }^{1-3}$ The morphological presentation varies widely and ranges from the historically typical echocardiographic pattern characterised by asymmetric septal hypertrophy with systolic anterior motion of the mitral valve to localised, and even total absence of, hypertrophic. ${ }^{34}$

Clinically, hypertrophic cardiomyopathy may present with a variety of symptoms such as dyspnoea on exertion, atypical chest pain, palpitations, presyncope, and syncope. ${ }^{23}$ In addition, asymptomatic forms have been well documented. ${ }^{23}$ Older patients may die of congestive cardiac failure. ${ }^{23}$ Sudden cardiac 
death, however, is the most feared consequence of this disorder, as it is the most common cause of death, affecting a young age group (5-40 years)..$^{2-5}$ Among young athletes, hypertrophic cardiomyopathy is responsible for at least $50 \%$ of all cases of sudden cardiac death. ${ }^{6}$

In familial hypertrophic cardiomyopathy, which constitutes more than $50 \%$ of all cases of hypertrophic cardiomyopathy, sudden cardiac death is particularly prevalent in certain pedigrees. ${ }^{78}$

Echocardiography, the established technique for the diagnosis of hypertrophic cardiomyopathy, has no predictive value with respect to the occurrence of sudden cardiac death. Neither has electrocardiography (ECG), even though electrocardiogram abnormalities often precede the development of ventricular hypertrophy and in some cases may predict the extent of hypertrophy that will develop. ${ }^{9}$

Until recently, the predictors of sudden cardiac death were syncope, a "malignant" family history, and the presence of nonsustained ventricular tachycardia on Holter monitoring. ${ }^{810-12}$

Elucidation of the molecular basis of familial hypertrophic cardiomyopathy may help unravel these diagnostic and prognostic complexities. Recently, locus and allelic heterogeneity have been demonstrated. Familial hypertrophic cardiomyopathy has been linked to distinct loci on chromosomes $1 \mathrm{q} 3,{ }^{13} 11 \mathrm{p} 13-$ $\mathrm{q} 13,{ }^{14} 14 \mathrm{q} 1,{ }^{15-17}$ and $15 \mathrm{q} 22^{18}$ but, with the exception of the $\beta$ myosin heavy chain $(\beta$ MHC) gene on chromosome $14 \mathrm{q} 1$, the responsible genes remain to be identified. At least 17 different missense mutations have been described to date in the $\beta$ MHC gene. ${ }^{19} 20$ Many of these occur at amino acid residues highly conserved through evolution. ${ }^{21}$

Several recently published studies suggest that specific $\beta$ MHC gene mutations generally correlate with prognosis. ${ }^{722}$ This information is presently used to provide counselling for affected families. Most studies, however, have been performed in Caucasian families in the northern hemisphere and it is not known whether a specific mutation will have a similar effect when present in people with different genetic or environmental backgrounds. Furthermore, the tendency to study pedigrees with multiple clinically affected individuals for genotype phenotype correlations may lead to an over interpretation of the risk attached to a certain mutation. For definition of the true risk, it may be more appropriate to select family members through genotyping, after which the full clinical spectrum can be evaluated in those individuals carrying the mutation.

In this study, we describe the clinical spectrum and prognosis associated with distinct $\beta$ MHC gene mutations in two South African pedigrees of mixed racial descent. The mutations assessed were Arg249Gln and the Arg403Trp, the latter mutation described independently by our group and Dausse et al. ${ }^{2324}$

\section{Patients and methods}

SELECTION OF SUBJECTS

Individuals of two non-related pedigrees were selected through the presence of $\beta$ MHC gene mutations. In the case of pedigree 106 previous studies linked the disease to the $\beta \mathrm{MHC}$ gene on chromosome $14 .{ }^{25}$ Subsequent single strand conformation polymorphism (SSCP) screening and sequencing of the $\beta$ MHC gene in the probands of pedigree $106^{23}$ and 108 identified the particular mutations and further selection of individuals was through polymerase chain reaction (PCR) based mutational assay.

This study was approved by the University of Stellenbosch Ethics Committee. Informed consent was obtained from participating individuals after a detailed description of the procedures.

\section{SOURCE OF DNA AND DNA EXTRACTION}

Peripheral blood for genotypic analysis was collected in tubes containing ethylenediamine tetraacetic acid (EDTA) from all blood relatives and DNA was extracted from nucleated blood cells as described previously. ${ }^{26}$

In one case of early death (pedigree 108: III-16) paraffin embedded formalin fixed liver tissue from a postmortem examination in 1982 was used for DNA extraction according to the method described by Shibata et al. ${ }^{27}$

\section{DETECTION OF $\beta$ MHC GENE MUTATION}

Single base substitutions were detected in the two probands during screening of individuals with hypertrophic cardiomyopathy for the presence of mutations in the $\beta$ MHC gene. This screening programme involved PCR amplification of exons $9,13,14,16$, and 23 of the $\beta$ MHC gene (exons which have previously been reported to contain mutations ${ }^{7} 1920$ ) followed by single strand conformation polymorphism (SSCP) analysis.

Exons 9 and 13 were PCR amplified using the following primer pairs which were designed with the aid of the OLIGO and PRIMER computer programmes using published $\beta$ MHC gene sequences ${ }^{28}$ : Exon 9:

MY9F80:

\section{5'ACTCATCACCACTCTCTTCC-3}

\section{MY9R188:}

\section{5'ATTCATGGCACTCACAGG-3'}

\section{Exon 13:}

MY13F47:

\section{5'CCAACTTTGCTACTTGCC-3}

MY13R196:

\section{5'CCTGCTGGACATTCTGC-3}

Amplification conditions for both sets of primers were: $1 \mu \mathrm{g}$ of genomic DNA template was amplified in a final volume of $25 \mu \mathrm{l}(50 \mu \mathrm{l}$ in the case of paraffin slice extracted template), containing $50 \mathrm{pmol}$ of each primer, $1 \mathrm{U}$ of Taq polymerase (Promega, Madison, Wisconsin), $1.5 \mathrm{mmol} / \mathrm{l}$ magnesium chloride, $75 \mu \mathrm{mol} / 1$ of each deoxyribonucleotide triphosphate (dNTP), $50 \mathrm{mmol} / 1$ potassium chloride, $10 \mathrm{mmol} / 1$ tris (hydroxymethyl) methylamine-hydrochloric acid $(\mathrm{pH} 9$ at $25^{\circ} \mathrm{C}$ ), and $0.1 \%$ Triton X-100 (BDH Chemicals, Poole), overlayed with $30 \mu 1$ 
mineral oil to prevent evaporation. Cycling conditions were: $93^{\circ} \mathrm{C}$ for $2 \mathrm{~min}$, followed by 30 cycles of $93^{\circ} \mathrm{C}$ for $100 \mathrm{~s}, 54^{\circ} \mathrm{C}$ for $120 \mathrm{~s}$, and $72^{\circ} \mathrm{C}$ for $160 \mathrm{~s}$ in a university PCR machine (ESU Electronics, Cape Town).

For SSCP analysis $5 \mu \mathrm{l}$ aliquots of the amplified samples were placed into Eppendorf tubes and $5 \mu \mathrm{l}$ of formamide loading dye ( $95 \%$ formamide, $0.02 \%$ bromophenol blue, $0.02 \%$ xylene cyanol, $10 \mathrm{mmol} / 1$ sodium hydroxide, $20 \mathrm{mmol} / \mathrm{l}$ EDTA) were added to each tube. Samples were subsequently denatured by heating at $95^{\circ} \mathrm{C}$ for $3 \mathrm{~min}$, loaded directly onto a $0.5 \times \mathrm{MDE}$ gel solution (AT Biochemicals, Malvern, Pennsylvania) and subjected to electrophoresis for $4 \mathrm{~h}$ at $50 \mathrm{~W}$ at $4^{\circ} \mathrm{C}$ in $0.5 \times \mathrm{TBE}(1 \times \mathrm{TBE}$ is 89 $\mathrm{mmol} / \mathrm{l}$ tris (hydroxymethyl) methylaminehydroxide, $89 \mathrm{mmol} / 1$ borate, and $2 \mathrm{mmol} / \mathrm{l}$ EDTA, at pH 8 and $25^{\circ} \mathrm{C}$ ) running buffer. Bands were visualised by silver staining of the gels.

Some $50 \mu 1$ of PCR amplified samples exhibiting SSCPs were purified using Magic PCR Preps DNA purification system (Promega) according to the manufacturer's protocol. The samples were subsequently precipitated with ethanol and resuspended in $8 \mu \mathrm{l}$ of water, of which $1 \mu \mathrm{l}$ was used as template in direct PCR sequencing with Promega fmol DNA sequencing system according to the manufacturer's instructions. Sequencing was performed in forward and reverse directions using ${ }^{32} \mathrm{P}$ end labelled $\mathrm{PCR}$ primers.

\section{GENOTYPIC ANALYSIS OF FAMILY MEMBERS}

PCR based detection of the specific mutations, which resulted in altered restriction enzyme recognition sequences, was used to determine genotypically affected family members.

Some $5 \mu$ of each PCR amplified sample $(20 \mu \mathrm{l}$ in the case of the paraffin embedded tissue sample) was microdialysed against deionised water for $15 \mathrm{~min}$ using VS $0.025 \mu \mathrm{m}$

Figure 1 Genotypic analysis by polymerase chain reaction (PCR) based mutation detection. Taq 1 digestion of the PCR amplified 109 bp product of exon 9 of the $\beta$ myosin heavy chain gene in a representative subset of pedigree 108. An internal Taq 1 site generates a 65 bp and $a 44$ bp fragment in unaffected individuals, the $G$ to $A$ transition in the Arg249Gln mutation destroys this site, yielding an additional $109 \mathrm{bp}$ fragment in affected heterozygotes.

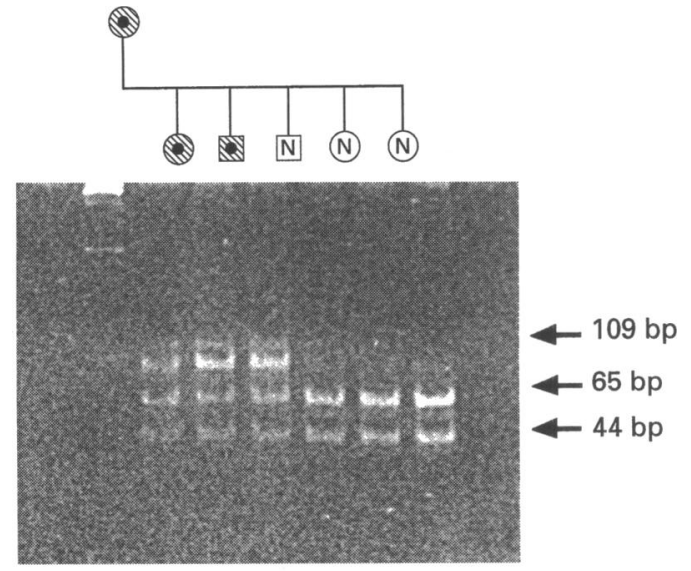

N(N) Mutation absent

Mutation present clinically affected filters (Millipore, Bedford, Massachusetts). Each dialysed sample was digested with $4 \mathrm{U}$ of the appropriate enzyme (Ava 1 in the case of the Arg403Trp mutation, and Taq 1 in the case of the Arg249Gln mutation) in the manufacturer's buffer (Promega) in a final volume of $10 \mu \mathrm{l}$ (30 $\mu \mathrm{l}$ for the paraffin embedded tissue sample). Digestion was performed for $2 \mathrm{~h}$ at $37^{\circ} \mathrm{C}$ (Ava 1) and $65^{\circ} \mathrm{C}(\operatorname{Taq} 1)$ and digested samples were subjected to electrophoresis on $12 \%$ polyacrylamide gels in $1 \times$ TBE running buffer at $10 \mathrm{~V} / \mathrm{cm}$ for $1.5 \mathrm{~h}$. The DNA fragments were visualised under ultraviolet light after ethidium bromide staining of the gels.

Genotypes were determined from the gels according to the following patterns: The 150 bp amplified exon 13 fragment was digested into a $100 \mathrm{bp}$ and a $50 \mathrm{bp}$ fragment by Ava 1 in genotypically unaffected individuals. The $\mathrm{C}$ to $T$ transition responsible for the Arg403Trp mutation destroyed this restriction enzyme site. Therefore, the presence of the Arg403Trp mutation in a heterozygous individual resulted in an additional uncut $150 \mathrm{bp}$ fragment.

The $109 \mathrm{bp}$ amplified fragment of exon 9 was digested into a $65 \mathrm{bp}$ and $44 \mathrm{bp}$ fragment by Taq 1 in genotypically unaffected individuals. The $G$ to $A$ transition responsible for the Arg249Gln mutation destroyed this restriction enzyme site. Therefore, the presence of the Arg249Gin mutation in a heterozygous individual resulted in an additional uncut 109 bp fragment (fig 1). Homozygotes were not detected for either mutation.

\section{CLINICAL EVALUATION}

A family history and clinical records were obtained to identify the number of sudden cardiac deaths and disease related deaths.

Genotypically affected family members were screened for the presence of symptoms and signs known to occur in hypertrophic cardiomyopathy. ${ }^{2329}$ Subsequently, standard twelve lead ECG and echocardiographic diagnostic investigations were performed.

Echocardiographic evaluation was performed with an Ultramark 4 scanner with a $3 \mathrm{MHz}$ transducer. Parasternal long and short axis views, together with apical four chamber and long axis views, were used to identify the presence and pattern of hypertrophy (similar to methods described previously). ${ }^{30}$ Standard diastolic measurements were taken with $M$ mode echocardiography. ${ }^{30}$ Pulsed wave Doppler studies were performed to detect the presence of intraventricular gradients and mitral incompetence. Echocardiographic diagnosis of hypertrophic cardiomyopathy was made on the presence of maximum ventricular wall thickness equal to or greater than $13 \mathrm{~mm}$, with reference to age adjusted tables in the case of children. ${ }^{31}$ Other echocardiographic changes previously described in hypertrophic cardiomyopathy ${ }^{29}$ were noted for each patient.

Electrocardiographic diagnosis of hypertrophic cardiomyopathy was based on the two most characteristic electrocardiogram 


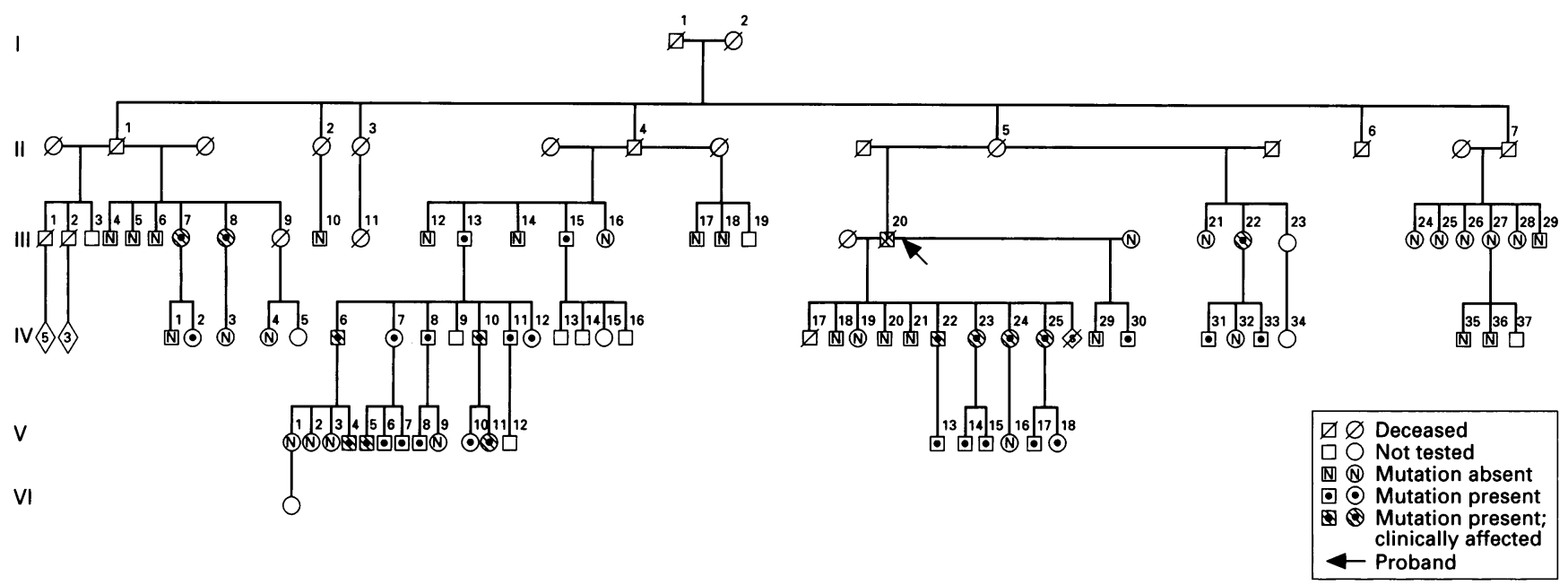

Figure 2 Pedigree 106 in which the Arg403Trp $\beta$-myosin heavy chain gene mutation is segregating. The genotypic and phenotypic status of family members is indicated in the key. The presence of the mutation was inferred in the proband (III-20). This patient died of congestive heart failure (aged 62 years) and clinical records clearly showed features of hypertrophic cardiomyopathy (table 1); no postmortem tissue was available.

presentations associated with this diseasethat is, left ventricular hypertrophy (according to the point system of Romhilt and Estes ${ }^{32}$ ) or abnormal $Q$ waves. Other electrocardiographic changes described for hypertrophic cardiomyopathy were noted in each patient. ${ }^{33}$

\section{Results}

DISEASE PENETRANCE AND CLINICAL PICTURE OF THE ARG403TRP MUTATION

Thirty one of the 64 related members of pedigree 106 subjected to genotypic analysis were positive for the Arg403Trp mutation. Additionally, a deceased family member (III20) was an obligate carrier by virtue of his position in the family tree (fig 2). Twenty of

Table 1 Clinical, electrocardiographic and echocardiographic data in family members of pedigree 106 carrying the Arg403Gln mutation

\begin{tabular}{|c|c|c|c|}
\hline Patient & Sex/Age (years) & Changes in ECG & $\begin{array}{l}\text { Echocardiographic } \\
\text { dimensions and changes }\end{array}$ \\
\hline \multicolumn{4}{|c|}{ ECG and echo abnormalities } \\
\hline III-7 & F 49 & LVH, LAH, Rep & \multirow{8}{*}{$\begin{array}{l}S=10 \mathrm{~mm}, \text { SAM } \\
S=13 \mathrm{~mm}, \text { ASH } \\
S=17 \mathrm{~mm}, \text { ASH } \\
\text { dilated } \mathrm{LA}, \text { SAM } \\
S=18 \mathrm{~mm}, \text { ASH } \\
S=14 \mathrm{~mm}, \text { ASH } \\
S=9 \mathrm{~mm}, \text { granular } \\
\text { pattern of S } \\
S=17 \mathrm{~mm}, \text { ASH } \\
S=5 \mathrm{~mm}, \text { granular } \\
\text { appearance of } S, \\
\text { myxomatous } \mathrm{MV}, \mathrm{MI}\end{array}$} \\
\hline III-8 & F 45 & LVH, LAH, RAH, Rep & \\
\hline III-20 & M 62 & LVH, LBBB & \\
\hline IV-22 & M 38 & LVH, LAH, LAD, Rep & \\
\hline IV-23 & F 36 & RAH & \\
\hline IV-24 & F 35 & LVH, RAH, Rep & \\
\hline IV-25 & F 32 & LVH, LAH, RAH, Rep & \\
\hline $\mathrm{V}-4$ & M 7 & Rep & \\
\hline \multicolumn{4}{|c|}{ Echo abnormalities only } \\
\hline IV-2 & F 17 & None & $\begin{array}{l}S=7 \mathrm{~mm} \text {, granular } \\
\text { appearance of } S\end{array}$ \\
\hline \multicolumn{4}{|c|}{ ECG abnormalities only } \\
\hline III-13 & M 60 & LAH & Normal \\
\hline III-22 & F 46 & LAH, RAH & Normal \\
\hline IV-6 & M 38 & Rep & Normal \\
\hline IV-10 & M 32 & LVH & Normal \\
\hline V-5 & M 17 & LVH & Normal \\
\hline $\mathrm{V}-11$ & F 3 & RVH & Normal \\
\hline \multicolumn{4}{|c|}{$\begin{array}{l}\text { No ECG or echo abnormalities } \\
\text { Seventeen individuals of whom } 10 \text { are aged less than } 16 \text { years }\end{array}$} \\
\hline
\end{tabular}

ASH $=$ asymmetric septal hypertrophy LA $=$ left atrium LAD $=$ left axis deviation LAH $=$ left atrial hypertrophy $\mathrm{LBBB}=$ left bundle branch block $\mathrm{LV}=$ left ventricle $\mathrm{LVH}=$ left ventricular atrial hypertrophy $\mathrm{LBBB}=$ left bundle branch block $L V=$ left ventricle $L V H=$ left ventricular
hypertrophy $\mathrm{MI}=$ mitral incompetence $M V=$ mitral valve $Q=$ abnormal $Q$ waves $R A H=$ right hypertrophy $\mathrm{MI}=$ mitral incompetence $M V=$ mitral valve $Q=$ abnormal $Q$ waves $R A H=$ right
atrial hypertrophy $\mathrm{S}=$ interventricular septum $\operatorname{Rep}=$ repolarisation disturbances $\mathrm{SAM}=$ atrial hypertrophy $S=$ interventricular septum Rep = repolarisation disturbances $S A M=$
systolic anterior motion of the mitral valve (anterior leaflet) $E C G=$ electrocardiogram $R V H=$ systolic anterior motion of the
right ventricular hypertrophy the genotypically affected individuals were 16 years or older (table 1 ).

Echocardiography was performed on the surviving 31 family members (table 1). Only four of this group met the strict echocardiographic criterion for hypertrophic cardiomyopathy with ventricular wall thickness equal to or greater than $13 \mathrm{~mm}$. Another four individuals had echocardiographic changes compatible with hypertrophic cardiomyopathy, but with ventricular wall thickness less than $13 \mathrm{~mm}$. Only one child (V-4) (aged 7 years) featured echocardiographic changes characteristic of hypertrophic cardiomyopathy. The echocardiogram of the deceased person (III-20), performed at another centre, indicated asymmetric septal hypertrophic $(17 \mathrm{~mm})$ with left atrial dilatation in the absence of valvular disease.

Of the 31 individuals examined by ECG, 14 demonstrated abnormalities. Eight of these had classic left ventricular hypertrophy as defined by the criteria of Romhilt and Estes. ${ }^{32}$ None of the latter was a child. Only two children had electrocardiogram changes, one (V11) (aged 3 years) showing right ventricular hypertrophy, the other $(\mathrm{V}-4)$ repolarisation abnormalities.

The disease penetrance of the Arg403Trp mutation in pedigree 106 , when evaluated by different criteria in two age groups, was: (1) for 20 people equal to or greater than 16 years: $25 \%$ by echocardiography (using the strict criterion of ventricular wall thickness equal to or greater than $13 \mathrm{~mm}$ ), $45 \%$ by echocardiography when including all changes compatible with hypertrophic cardiomyopathy, ${ }^{29} 40 \%$ by ECG (using the strict criterion of left ventricular hypertrophy), and $60 \%$ by ECG when including all changes compatible with hypertrophic cardiomyopathy ${ }^{33}$; and (2) for children less than 16 years: $8 \%$ by echocardiography and $16 \%$ by ECG.

Clinical events were rare in this family without a single case of sudden cardiac death or syncope occurring. One person reported a presyncopal attack (IV-33) and one person died of cardiac failure, secondary to familial 
Figure 3 Pedigree 108 in which the Arg249Gln $\beta$-myosin heavy chain gene mutation is segregating. The genotypic and phenotypic status of family members is indicated in the key. Individual II-4, who died of cancer of the larynx, was an obligate heterozygote by virtue of his position in the pedigree and clinical records confirmed the presence of hypertrophic cardiomyopathy (table 2).

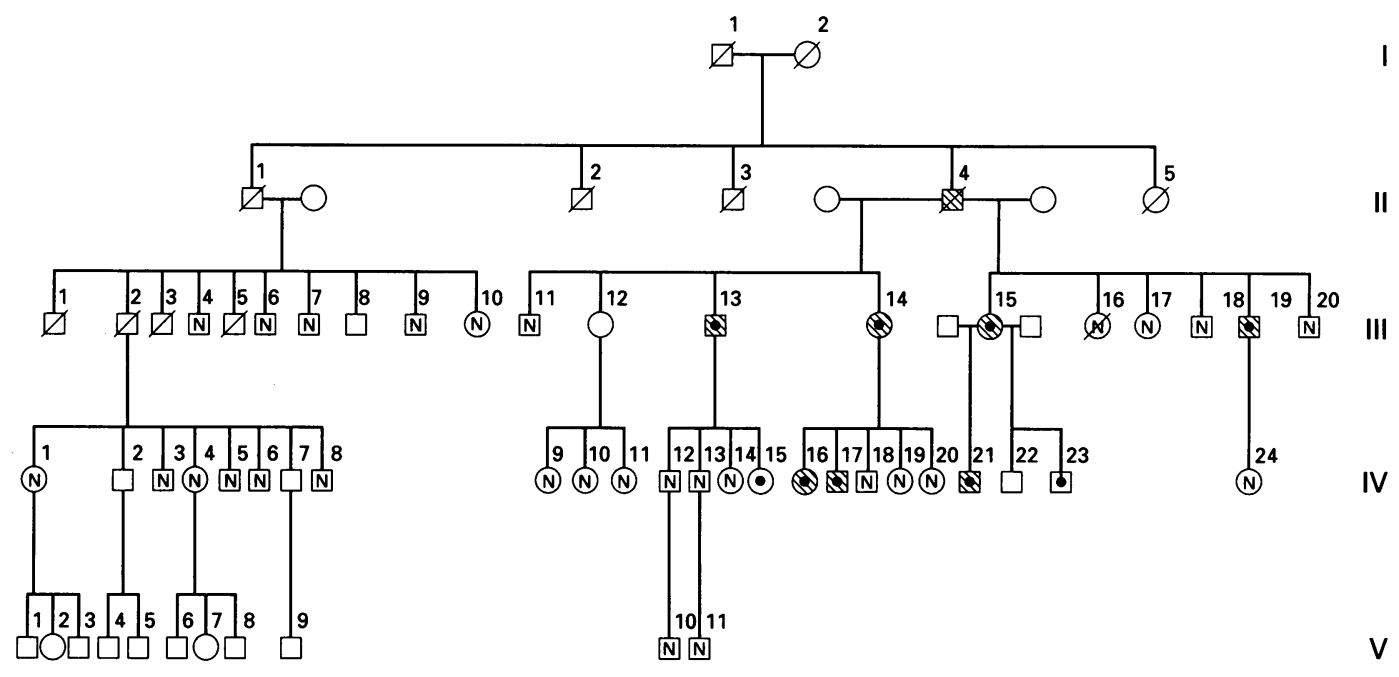

$\triangle \varnothing$ Deceased

$\square$ Not tested

N (N) Mutation absent

- - Mutation present

$\otimes$ Mutation present clinically affected hypertrophic cardiomyopathy, at the age of 62 years (III-20). One child (IV-17) died at the age of 3 years with a diagnosis of meningitis, but no clinical records or postmortem material were available for further investigation. Nine individuals were symptomatic, but the symptoms were often mild. Only five individuals had clinical signs on physical examination that were compatible with familial hypertrophic cardiomyopathy, all of whom featured abnormal electrocardiograms or echocardiograms, or both. A family history revealed that individuals II-2, II-3 and II-6 all died of a "heart condition" when aged about 70 years or older. In generation III, individuals III-1 and III-2 died of unknown causes when aged between 60 and 70 years, while III-11 died of tuberculosis aged 19 years.

In summary, the Arg403Trp mutation in pedigree 106 was associated with a low penetrance rate on echocardiography as well as

Table 2 Clinical, electrocardiographic and echocardiographic findings in family members of pedigree 108 carrying the Arg249Gln mutation

\begin{tabular}{|c|c|c|c|}
\hline Patient & Sex/Age (years) & Changes in $E C G$ & $\begin{array}{l}\text { Echocardiographic } \\
\text { dimensions and changes }\end{array}$ \\
\hline II-4 & $\begin{array}{l}\text { M } 68 \\
\text { at death }\end{array}$ & LVH, Q LAH, LAD, Rep & $\begin{array}{l}\text { Echocardiogram } \\
\text { not available }\end{array}$ \\
\hline III-13 & M 48 & LBBB & Normal \\
\hline III-14 & F 46 & LVH, LAH, RAH, Rep & $\mathrm{S}=15 \mathrm{~mm}, \mathrm{ASH}$ \\
\hline III-15 & F 40 & LVH, LAH, RAH, Rep & $\mathrm{S}=26 \mathrm{~mm}, \mathrm{ASH}, \mathrm{SAM}$ \\
\hline III-19 & M 32 & $\operatorname{Rep}$ & $\begin{array}{l}S=12 \mathrm{~mm} \text {, hypertrophic } \\
\text { appearance of LV }\end{array}$ \\
\hline IV-15 & F 13 & None & Normal \\
\hline IV-16 & F 22 & RAH, Rep & $\begin{array}{l}\mathrm{S}=11 \mathrm{~mm} \text {, hypertrophic } \\
\text { appearance of } \mathrm{LV}\end{array}$ \\
\hline IV-17 & M 21 & LVH, Rep & $\mathrm{S}=10 \mathrm{~mm}$, granular \\
\hline $\begin{array}{l}\text { IV-21 } \\
\text { IV-23 }\end{array}$ & $\begin{array}{l}\text { M } 22 \\
\text { M } 14\end{array}$ & $\begin{array}{l}\text { LVH, Q, LAH, RAH, Rep } \\
\text { None }\end{array}$ & $\begin{array}{l}S=23 \mathrm{~mm}, \mathrm{ASH} \\
\text { Normal }\end{array}$ \\
\hline
\end{tabular}

ASH $=$ asymmetric septal hypertrophy $\mathrm{LA}=$ left atrium $\mathrm{LAD}=$ left axis deviation $\mathrm{LAH}=$ left atrial hypertrophy $L B B B=$ left bundle branch block $L V=$ left ventricle $L V H=$ left ventricula hypertrophy $M I=$ mitral incompetence $M V=$ mitral valve $Q=$ abnormal $Q$ waves $R A H=$ righ atrial hypertrophy $S=$ interventricular septum Rep = repolarisation disturbances $S A M=$ systolic anterior motion of the mitral valve (anterior leaflet) $E C G=$ electrocardiogram $R V H=$ right ventricular hypertrophy

ECG. The cumulative incidence of cardiac events was very low.

DISEASE PENETRANCE AND CLINICAL PICTURE OF THE ARG249GLN MUTATION

Nine of the 37 related members of pedigree 108 subjected to genotypic analysis were positive for the Arg249Gin mutation. Additionally, a deceased family member, (II-4) was an obligate carrier by virtue of his position in the family tree. Two of the genotypically affected individuals were children (a boy (V-23) aged 14 years and a girl (IV-15) aged 13 years) (fig 3). Genotypic analysis by PCR amplification of archival postmortem tissue showed individual III-16 not to be carrying the Arg249Gln mutation.

Echocardiography was performed on all nine surviving family members, seven of these in our echocardiography laboratory (table 2). Only three of these satisfied the criteria of hypertrophic cardiomyopathy with ventricular wall thickness equal to or greater than $13 \mathrm{~mm}$. Another three individuals showed abnormalities compatible with hypertrophic cardiomyopathy, but all of these had ventricular wall thickness less than $13 \mathrm{~mm}$. The two children demonstrated normal echocardiograms. The remaining individual (tested elsewhere) featured no echocardiographic abnormalities. No echocardiogram was available for the deceased person (II-4).

Abnormal electrocardiogram features were present in eight of the 10 individuals tested. Only the children showed no electrocardiogram abnormalities. Five individuals demonstrated classic left ventricular hypertrophy. ${ }^{32}$ One person had a combination of repolarisation disturbances and right atrial hypertrophy (IV-16), another person had only repolarisation abnormalities (III-19), and the remaining individual had a left bundle branch block (III-13). 
This family was treated as a single group when calculating the disease penetrance of the Arg249Gln mutation, as there were only two teenagers less than 16 years. The results, when evaluated by different criteria, were: $33 \%$ by echocardiography (using the strict criterion of ventricular wall thickness equal to or greater than $13 \mathrm{~mm}$ ), $67 \%$ by echocardiography when taking into account all minor changes, ${ }^{29} 50 \%$ by ECG (using the strict criterion of left ventricular hypertrophy), and $80 \%$ by ECG when including all changes compatible with hypertrophic cardiomyopathy.

Cardiac clinical events were rare in this family. The deceased obligate carrier died as a result of cancer of the larynx (aged 68 years). Not one single case of sudden cardiac death or syncope occurred, although three persons reported presyncopal attacks (III-14, IV-16, and IV-21). Eight of the 10 people were symptomatic, however, with chest pain and dyspnoea being the most frequent complaints. Both children were asymptomatic. Clinical examination showed abnormalities compatible with hypertrophic cardiomyopathy in four individuals. A family history revealed that individuals II-2 and II-3 died of respiratory disease, when aged $>60$ and $>70$ years respectively, while individual II-5 died at about 2 years of age of unknown causes.

In summary, the Arg249Gln mutation in this family was associated with a partial penetrance rate when assessed by echocardiography (using the strict criterion) but with a high penetrance rate when evaluated by ECG. The cumulative incidence of cardiac events was very low.

\section{Discussion}

Two pedigrees with different $\beta$ MHC gene mutations were identified (pedigree 106: Arg403Trp; pedigree 108: Arg249Gln). Both families were of mixed racial ancestry and lived in the same geographical area, the Western Cape region of South Africa.

The wide variation in the clinical picture in familial hypertrophic cardiomyopathy described previously 722 was confirmed in both pedigrees. Although the clinical picture in pedigree 108 seemed more severe than in pedigree 106, the significance of this observation is not clear. The clinical course in both families was uniformly benign, however, with a very low incidence of cardiac events (presyncope, syncope, and sudden cardiac death). The only death occurring as a result of familial hypertrophic cardiomyopathy was in a 62 year old man (pedigree 106, III-20). Although it proved difficult, and sometimes impossible, to obtain information on relatives in the earlier generations, we are reasonably certain that the frequency of sudden cardiac death at a young age (less than 40 years) was very low, or even non-existent, in each pedigree.

A comparison was made between pedigree 106 and pedigree 730, the latter a European family described by Dausse et $a l^{24}$ who also carried the Arg403Trp mutation. Pedigree 730 also exhibited partial penetrance, with
ECG clearly being the more sensitive diagnostic procedure. Ventricular hypertrophy was moderate in both pedigrees, with maximum ventricular wall thickness of $17 \mathrm{~mm}$ and 18 $\mathrm{mm}$ for pedigrees 730 and 106 respectively. Both kindreds featured a very low incidence of cardiac events, without a single case of sudden cardiac death.

Several factors have to be taken into consideration when making a comparison of pedigrees 108 and $Q Q$, both carrying the Arg249Gln mutation. The latter kindred was a European family described by Watkins et al. ${ }^{7}$ Pedigree QQ was larger than pedigree 108, comprising 24 and 10 genotypically affected individuals respectively. A much higher incidence of familial hypertrophic cardiomyopathy related deaths, $10(42 \%)$, of which four were sudden cardiac deaths $(17 \%)$, was observed in pedigree $\mathrm{QQ}$, while no such cases occurred in pedigree 108. The mean age of death in pedigree $Q Q$ was 49 years, however, in pedigree 108 only one affected individual (II-4) was older than 49. Nevertheless, the total absence of sudden cardiac deaths attributable to familial hypertrophic cardiomyopathy among ten genotypically affected members of this pedigree, with a mean age of 33 years, remains an interesting finding.

At present, it is difficult to draw a conclusion regarding the severity of familial hypertrophic cardiomyopathy caused by the Arg249Gln mutation in pedigree 108 compared with that in pedigree $\mathrm{QQ}$. Nevertheless, longitudinal follow up studies of the identified family should provide valuable information concerning the prognosis associated with the Arg249Gln mutation in future.

Interestingly, in pedigree 106 the penetrance and severity of the clinical picture decreased beyond the confines of the originally identified nuclear family with multiple clinically affected individuals, of whom III-20 was the proband (fig 2, table 1). In general, variation in the clinical picture of familial hypertrophic cardiomyopathy within and between families has been well documented. A possible explanation for the altered expression of identical $\beta$ MHC gene mutations is the effect of modifying genes. This suggests that a combination of permissive genes may be necessary to allow full expression of the $\beta$ MHC gene mutation. Another explanation for altered expression of a mutation could be environmental factors, which modify gene expression. ${ }^{20} 34$

This study emphasises the importance of confirming genotype phenotype correlations for distinct $\beta$ MHC mutations, especially in large pedigrees of different ethnic origin. Establishing such associations will provide a valuable information source when counselling affected families.

1 Maron BJ, Bonow RO, Cannon RO, Leon MB, Epstein SE. Hypertrophic cardiomyopathy: interrelations of clinical manifestations, pathophysiology and therapy (first of two parts). N Engl $\mathcal{F}$ Med 1987;316:780-9.

2 Maron BJ, Bonow RO, Cannon RO, Leon MB, Epstein SE. Hypertrophic cardiomyopathy: interrelations of 
clinical manifestations, pathophysiology, and therapy (second of two parts). N Engl F Med 1987;316:844-52.

3 Lawson JWR. South-western internal medicine conference: hypertrophic cardiomyopathy: current views on etiology, pathophysiology and management. $A m \mathcal{F ~ M e d}$ Sci 1987;294:191-210.

4 McKenna WS. Hypertrophic cardiomyopathy. In: Julian DG, Camm AS, Fox KM, Hall RJC, Poole-Wilson, eds. Diseases of the heart. London: Bouilliere Trindall, 1989:9233-50.

5 McKenna W, Deanfield J, Faruqui A, England D, Oakley C, Goodwin J. Prognosis in hypertrophic cardiomyopathy: role of age and clinical electrocardiographic and pathy: role of age and clinical, electrocardiographic and

6 Maron BJ, Roberts WC, McAllister HA, Rosing DR Epstein SE. Sudden death in young athletes. Circulation 1980;62:218-29.

7 Watkins H, Rosenzweig A, Hwang D-S, et al. Characteristics and prognostic implications of myosin missense mutations in familial hypertrophic cardiomyopathy. N Engl f Med 1992;326:1108-14.

8 Maron BJ, Lipson LC, Roberts WC, Savage DD, Epstein SE. "Malignant" hypertrophic cardiomyopathy: identification of a subgroup of families with unusually frequent premature death. Am $₹$ Cardiol 1978;41:1133-40.

9 Panza JA, Maron BJ. Relation of electrocardiographic abnormalities to evolving left ventricular hypertrophy in hypertrophic cardiomyopathy during childhood. Am $f$ Cardiol 1989;63:1258-65.

10 McKenna WJ, Camm AJ. Sudden death in hypertrophic cardiomyopathy: assessment of patients at high risk. Circulation 1989;80:1489-92.

11 McKenna WJ, England D, Doi YL, Deanfield JE, Oakley CE, Goodwin JF. Arrhythmia in hypertrophic cardiomyopathy. Br Heart f 1981;46:168-72.

12 Maron BJ, Savage DD, Wolfson JK, Epstein SE Prognostic significance of 24 hour ambulatory electrocardiographic monitoring in patients with hypertrophic cardiomyopathy: a prospective study. Am $₹$ Cardiol cardiomyopathy:

13 Watkins H, MacRae C, Thierfelder L, et al. A disease locus for familial hypertrophic cardiomyopathy maps to chromosome 1q3. Nature Genet 1993;3:333-7.

14 Carrier L, Hengstenberg C, Beckmann JS, et al. Mapping of a novel gene for familial hypertrophic cardiomyopathy to chromosome 11. Nature Genet 1993;4:311-3.

15 Jarcho JA, McKenna W, Pare JAP, et al. Mapping a gene for familial hypertrophic cardiomyopathy to chromofor familial hypertrophic cardiomyopathy

16 Hejtmancik JF, Brink PA, Towbin J, et al. Localisation of a gene for familial hypertrophic cardiomyopathy to chromosome $14 \mathrm{q} 1$ in a diverse US population. Circulation 1991;83:1592-7.

17 Epstein ND, Fananapazir L, Lin HJ, et al. Evidence of genetic heterogeneity in five kindreds with familial hypertrophic cardiomyopathy. Circulation 1992;85: 635-47.

18 Thierfelder L, MacRae C, Watkins $\mathrm{H}$, et al. A familial hypertrophic cardiomyopathy locus maps to chromosome 15q2. Proc Natl Acad Sci USA 1993;90:6270-4.
19 Hengstenberg C, Komajda M, Schwartz K. Genetics of familial hypertrophic cardiomyopathy: results and stratefamilial hypertrophic cardiomyopathy: results and stra

20 Fananapazir L, Epstein ND. Genotype-phenotype correlations in hypertrophic cardiomyopathy: insights provided by comparisons of kindreds with distinct and identical $\beta$ MHC gene mutations. Circulation 1994;89:22-32.

21 Geisterfer-Lowrance AAT, Kass S, Tanigawa G, et al. A molecular basis for familial hypertrophic cardiomyopathy: a $\beta$-cardiac myosin heavy chain gene missense mutation. Cell 1990;62:999-1006.

22 Epstein ND, Cohn GM, Cyran F, Fananapazir L. Differences in clinical expression of hypertrophic cardiomyopathy associated with two distinct mutations in the $\beta$-myosin heavy chain gene. Circulation 1992;86: the $\beta$-my

23 Moolman JC, Brink PA, Corfield VA. Identification of a new missense mutation at Arg403, a CpG mutation hotspot, in exon 13 of the $\beta$-myosin heavy chain gene in hypertrophic cardiomyopathy. Hum Mol Genet 1993;9: 1731-2.

24 Dausse E, Komajda M, Fetler L, et al. Familial hypertrophic cardiomyopathy: microsatellite haplotyping and identification of a hot spot for mutations in the $\beta$-myosin heavy chain gene. $¥$ Clin Invest 1993;92:2807-13.

25 Moolman JC, Ferreira A, Hirschfield W, Hunter J, Corfield VA. Genetic studies of the cardiac myosin heavy chain gene locus in South African families with heavy chain gene locus in South African families with hypertrophic cardiomyopathy evidence for genetic
heterogeneity. Cardiovasc $¥$ Southern Africa $1994 ; 5: 6-11$.

26 Corfield VA, Moolman JC, Martell R, Brink PA Polymerase chain reaction based detection of $M N$ blood group specific sequences in the human genome. Transfusion 1993;33:119-24.

27 Shibata DK, Arnheim M, Markin WJ. Detection of human papilloma virus in paraffin embedded tissue using the polymerase chain reaction. $f$ Exp Med 1988 ; 167:225-30.

28 Jaenicke T, Diederich KW, Haas W, et al. The complete sequence of the human beta-myosin heavy chain gene. Genomics 1990;8:194-206.

29 Braunwald E. Heart disease, a textbook of cardiovascular medicine. Philadelphia: WB Saunders, 1992:1404-15.

30 Maron BJ, Gottdiener JS, Epstein SE. Patterns and signifcance of distribution of left ventricular hypertrophy in hypertrophic cardiomyopathy: a wide-angle, two-dimen sional echocardiographic study of 125 patients. $A m$ Cardiol 1981;48:418-28.

31 Feigenbaum H. Echocardiography, 3rd ed. Philadelphia: Lea-Febiger, 1981:551-2.

32 Romhilt DW, Estes EH. A point score system for the ECG diagnosis of left ventricular hypertrophy. Am Heart 1968;75:752-8

33 Savage DD, Seides SF, Clark CE, et al. Electrocardiographic findings in patients with obstructive and nonobstructive hypertrophic cardiomyopathy. Circulation 1978;58:402-8.

34 Hengstenberg C, Schwartz K. Molecular genetics of familial hypertrophic cardiomyopathy. $\mathcal{f}$ Mol Cell Cardiol 1994;26:3-10. 